\title{
The Parental Attitude towards Adolescent Sexual Behaviour in Akoko-Edo and Estako-West Local Government Areas, Edo State, Nigeria
}

\author{
Martina A. Olubayo-Fatiregun ${ }^{1, *}$ \\ ${ }^{1}$ Dept of Physical and Health Education, Obafemi Awolowo University, Ile-Ife, Osun State, Nigeria \\ *Correspondence: Dept of Physical and Health Education, Obafemi Awolowo University, Ile-Ife, Osun State, \\ Nigeria. Tel: 234-803-450-7479. E-mail: martolufat@yahoo.co.uk
}

Received: July 10, 2012

Accepted: August 5, $2012 \quad$ Online Published: November 20, 2012

doi:10.5430/wje.v2n6p24

URL: http://dx.doi.org/10.5430/wje.v2n6p24

\begin{abstract}
The study examined the Parental Attitude towards Adolescent Sexual Behaviour in Akoko Edo and Estako - West Local Government Areas, Edo State, Nigeria. A descriptive survey research design was adopted for the study. The sample size of 600 parents; $350(58.39 \%)$ fathers and $250(41.7 \%)$ mothers was purposively selected from the from the two local government areas for the study. This was complemented with focus group discussion conducted with 20 (twenty) parents currently teaching in 8 secondary schools in the local government area of the study. Four research hypotheses were generated based on attitudinal topical areas. A self developed questionnaire and validated for its reliability at $\mathrm{R}=0.86$ was used to elicit responses from the participants. Data collected were coded and analyzed using descriptive statistics. The study revealed that some the four variables were significant. Based on the findings of the study, parents should be groomed on the importance of having interest in the adolelescent sexuality issue. This should be done through mass media, conferences and workshops. Government should make the course on adolescent reproductive health compulsory in all schools. Enlightenment campaign by NGO by other stake holders should be encouraged by the government - at both federal and state level.
\end{abstract}

Keywords: Sexuality; Behaviour; Parents; Attitude; Adolescent; Akoko-Edo; Estako-west

\section{Introduction}

Sex so small a word, yet is an explosive subject which people desperately want answers to related problems. Knowledge and attitude about sex is so vital that people seek it from whatever sources that are available, good or bad. When accurate information is not available, people will ignorantly accept misinformation for truth. This is especially noticeable among youth. The failure of adult to sex related issues openly with young people having several unfortunate consequences. However, reproductive health of both women and men has recently received special attention in many African Countries. Many governments have been concerned with various reproductive health matters of its people especially after the 1994 Cairo International Conference on Population and Development. A special focus has been directed towards parental attitudes towards reproductive health of adolescents due global consequences this group of people face in the bid to grow to maturity. Adolescent stage is a wonderful period in one's life and time filled with new and exciting things and inventions. Mensch, B. S, J. Bruce, M. E, Green (1998), stated that what happen between these ages $10-19$, whether good or bad shapes how girls and boys live out their lives as women and men. The researches further opined that it is therefore the task of all responsible parties to make sure that the transition from childhood to adulthood happens under favourable condition and environments.

Adolescent sexual and reproductive health is a critical important policy and programmatic issues in sub Saharan Africa given the generalized AIDs epidemic that has taken hold in many countries as well as a persistently high level of adolescent childbearing. An estimated $4.3 \%$ of young women and $1.5 \%$ of young men aged $15-24$ of young in sub - Saharan, were living with HIV while $9-13 \%$ young women had given birth by age 16 (Lloyd CB, 2005). Definitely young people need access to productive information and skills before they become sexually active in order to reduce their risk of contacting HIV and other Sexually Transmitted Infection (STIs) and experiencing unwanted pregnancies at very early childbearing age. 
Studies by CUI, and Ersheng, (2001), and National Guideline Taskforce 1996 have shown that parents who ought to be the primary educators of their children and communicate to them specific values about sexuality play the least role in this area. Parents have suggested that government agency would be best to provide comprehensive sexuality education, while parents suggested the school teachers; others considered sexuality education as being immoral, contrary to religious and traditional values and likely to encourage pre - marital sexual activity (Richard 2001). Sexual education and services for adolescents remains a controversial issue in Nigeria and a taboo in many communities. There is a wide spread fear even among the educated parents that discussing sexual issues might stimulate children's sexual interest. Moronkola and Idris (2000), were of the opinion that parents are not forthcoming as expected to act as primary sexuality educators for their children. Educational institutions also provide little or no sexuality education for young people and as such young children are left to the equally uninformed peers as the primary source of information on the issues.

Many factors could be deduced to be responsible for this laxity including the general belief that sexuality education will encourage promiscuity among the adolescents. With the absence of information from the right sources or expected sources, these boys/girls seek information from their peers, films, internet and mass media. This uninformed information drives the adolescents to imitate and put into practice whatever they watch, see, hear or read from other sources. These encourage risky sexual behavior which has serious consequences of unwanted pregnancy, abortion, early marriage, parenthood and contacting Sexually Transmitted Infections (STIs). Adolescents are the critical group of people in the society and country at large which needs protection from the dangers and implication of risky sexual behaviours through early and accurate information on sexual issues. This is very necessary if adolescents are to live and have a successful growth to adulthood. This study therefore focuses on the attitude of parents towards sexuality behaviour of their children in Edo - North senatorial district of Edo state, Nigeria.

\section{Statement of Problem}

There is a high rate of sexual abuse among adolescents in the society, secondary schools, tertiary and other institution of learning. These have resulted into unwanted pregnancies, teenage parenthood, illegitimate children, feeling of shame and emotional instability. In some cases, abortion is attempted or committed and this sometimes led to premature death of both mother and child. The primary cause of these lamentable circumstances is simply because adults in a position to instruct the young are too often filled with shame and guilt about sex. They are themselves sexually ignorant or misinformed and painfully uncertain about what they truly believe to be acceptable sex behaviour. Compounding this ignorance and conflict is their reluctance to admit these shortcomings. A growing proportion of youth not only initiates sexual intercourse at early ages, but also engages in multiple sexual partners for lack of information and education, hence a high incidence of illegally induced abortions. Moronkola and Fakeye (2008), reveal that sizeable number of youth have been sent out or shamefully and voluntarily withdrawn from school due to teenage pregnancy. The researchers further stated that many female adolescents may be engaging in unprotected sexual intercourse with attended health consequences because they lack knowledge and information.

Parents, who ought to communicate values about sexual behaviour to their teaming population of adolescent, shy away due to several opinion and beliefs. Against this background, this study sought to find answer to the following research questions:

1) Do parents have knowledge of perception of adolescent sexual behaviour?

2) What is the attitude of parents towards adolescents having access to reproductive health services?

3) Do the parents communicate with adolescents on sex related issues?

4) What is the attitude of parents to the introduction of sex/family education into schools curriculum where adolescents attend?

5) Who should be responsible for providing adolescents with sexuality information?

\section{Methodology}

\subsection{Research Design}

The descriptive survey design was used to examine parents attitude towards adolescent sexual behaviour.

\subsection{Population}

The population for this study comprised of parents from Akoko - Edo and Etsako West local government areas 
of north Senatorial district of Edo state.

\subsection{Sample and Sampling techniques}

The sample size for this study comprised of 600 parents, $350(58.3 \%)$ fathers and $250(41.7 \%)$ mothers randomly selected from the Akoko Edo and Estako were local government areas of north senatorial district of Edo State. This was complemented with focus group discussion (FGD) of 20 parents currently teaching in 8 secondary schools in the local government areas of study.

\subsection{Research Instrument}

Data for this study was derived using two instruments which is a self developed structured questionnaire and focus group discussion (FGDs) see abstract. The questionnaire validated with a reliability of 0.86 was used to collect responses from parents. A 4 point likert - type (Strongly Agreed (SA), Agreed (A), Disagreed (D) and Strongly Disagreed (SD)), questionnaire covering the following areas: - knowledge and perception of adolescents reproductive health issues, provision of services to adolescents, communication with adolescents on sexual behaviour and introduction of sex/family planning education into school curriculum. The focus group discussion (FGDs) was used for the qualitative aspect of the research, 20 parents currently teaching in 8 secondary schools were purposively selected and used for the focus group discussions (FGDs). This was to complement the questionnaire previously administered. This was followed by FGS comprising of 20 teacher parents arising teaching in 8 secondary school.

\subsection{Procedure}

Two instruments were administered to the participants at different times by the researcher and four research assistances. Five hundred and fifty $(88.7 \%)$ valid questionnaires were retrieved from the participants. The data collected were coded and analyzed using percentages.

\section{Result}

\subsection{Demographic Data}

Out of 550 parents who participated in the programme, $50(20 \%)$, were between 20 - 30 years, two hundred and fifty $(45.45 \%)$, were between $31-40$ years, one hundred and fifty $(27.27 \%)$, were between $41-50$ years and one hundred $(18.18 \%)$, were above 51 years. Out of 550 parents, three hundred $(54.55 \%)$, were male parents while two hundred and twenty (40\%), were female parents. Out of 550 parents, four hundred (76.36\%), were married, 80 $(14.55 \%)$, widows and $50(9.90 \%)$, claimed to be single. Out of 550 parents, Christians were three hundred $(54.55 \%)$, Muslims, one hundred (18.18\%), and 50 (9.90\%), never indicated their belief.

Research Questions1: Do parents have knowledge of adolescent sexual behaviour? 


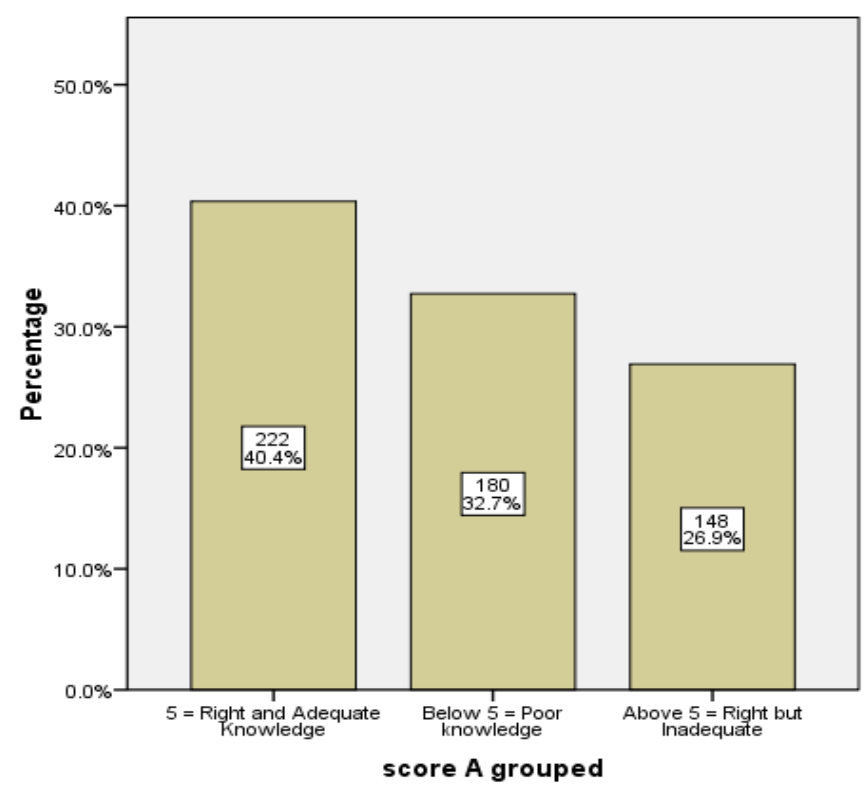

Bars show Percent

Figure 1: Parental knowledge of adolescent sexual behaviour

In figure 1, 222 parents (40.4\%), indicated right attitude towards adolescent sexual behaviour. While 180 parents $(32.3 \%)$, and 148 parents $(22.9 \%)$ respectively show a poor and inadequate knowledge towards adolescent sexual behaviour. service?

Research question 2: What is the attitude of parents towards adolescents having access to reproductive health

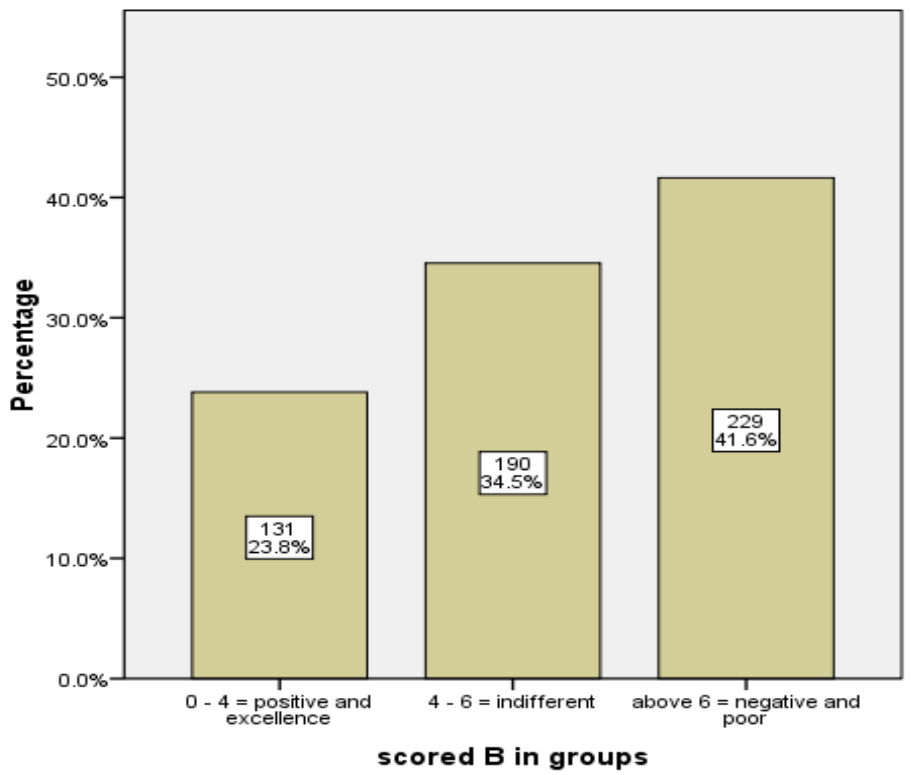

Bars show Percent

Figure 2: Parents attitude towards adolescents having access to reproductive health service

In figure 2 above, many parents 229 (41.6\%), shows a negative attitude towards having access to reproductive health services, 190 parents $(34.5 \%)$, are indifferent while a few number of parent with $131(23.8 \%)$, show a positive 
and excellent attitude.

Research question 3: Do parents communicate with their adolescent on sex related issues?

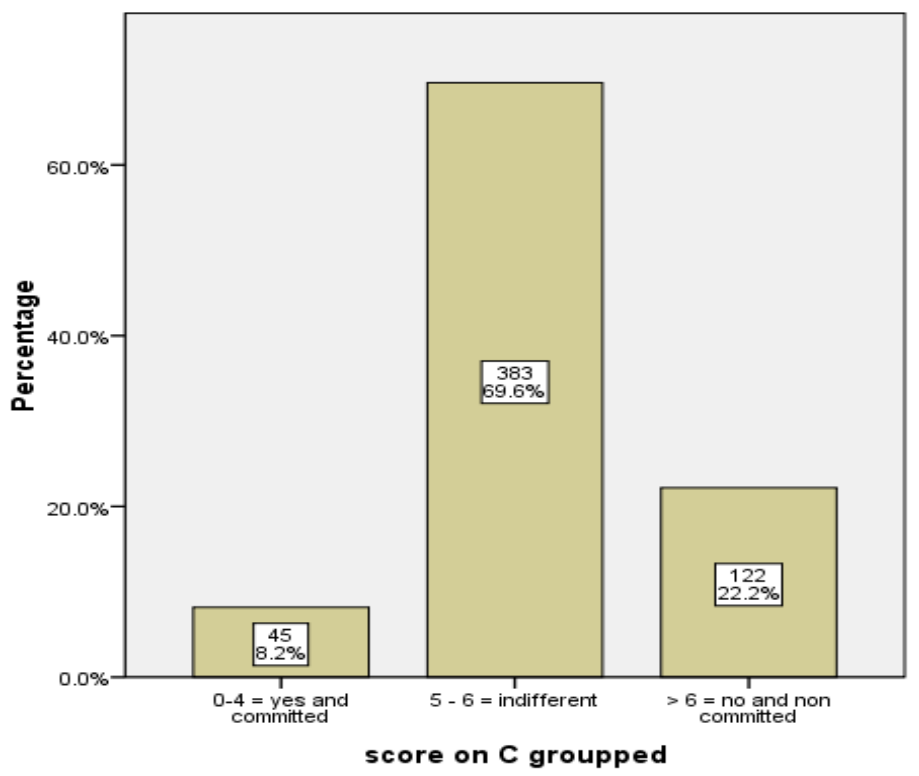

Bars show Percent

Figure 3: Communication of parents with adolescent on sex related issues?

Figure 3 reveal that 383 parents $(69.6 \%)$, out of the 550 used for this analysis are indifferent on communicating with their adolescent on sex related issues. This was followed by $122(22.2 \%)$, non - committed parents, while only 45 parents $(8.2 \%)$, showed up as committed parents who communicated with their adolescent on sexual related issues.

Research question 4: What is the Attitude of parents to the introduction of sex education into school curriculum where adolescents attend?

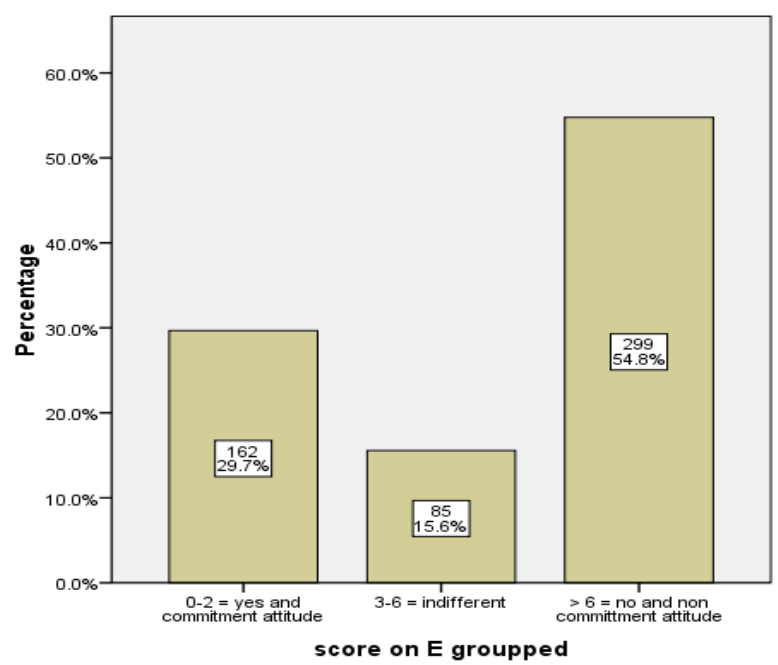

Bars show Percent

Figure 4: Attitude of parents to the introduction of sex education into schools curriculum where adolescents attend?

In figure 4 above, 299 parents (54.4\%), showed a negative attitude to the introduction of sex education into school's curriculum, 162 parents $(29.5 \%)$, showed a positive while 85 parents $(15.5 \%)$, showed indifference attitude. 4 parents did not indicate their opinion on the issues.

Research question 5: Who should be Responsible for providing adolescents with sexuality information? 


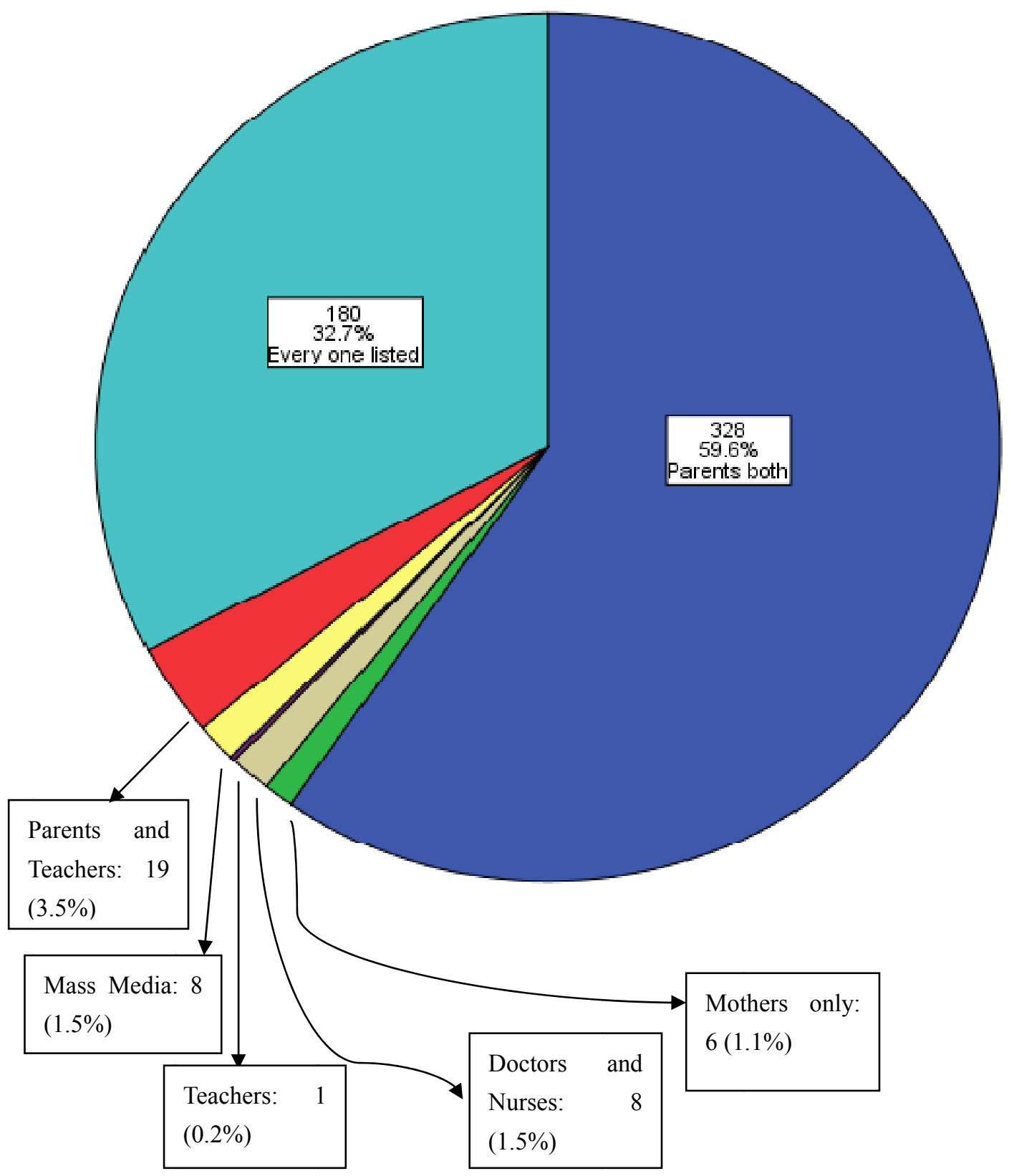

Who should be responsible for providing adolescents with sexuality information?

Parents both

mothers only doctors and nurse only Teachers

$\square$ Mass media

Harents and teachers

Every one listed

Pie Slices show Count

Figure 5: Who should be responsible for providing adolescent with sexuality information?

Figure 5 depicted above revealed that 328 parents $(59.5 \%)$, indicated that both parents should be involved in passing information, while 180 parents $(32.7 \%)$, indicated that all should be involved, with a minority 6 (1.1\%) suggested mothers only.

\section{Discussion}

As observed in figure 1, Parents knowledge of sexual behaviour of their adolescents revealed, 222 parents $(40.4 \%)$, had knowledge about the sexual behaviour of their adolescents. However some of the parents (32.7\%), and (26.9\%), had poor inadequate knowledge. This means majority of parents know that their adolescent children have boy/girl friends, while others have inadequate or no knowledge at all. This goes to compliment the focus group discussion where most parents agreed that they are aware that most adolescent have boy/girl friends. They however stated that since sexual activities are usually hidden practices, they may not necessarily be able to know whether or not their adolescents are sexually active. Minority of parents in the focus group discussion (FGDs) says no 
knowledge at all.

In response to the issues of attitude of parents towards adolescents and having access to reproductive health services, majority of parents $(41.6 \%)$, had negative and poor attitude. They felt that adolescents should not be encouraged in obtaining reproductive health services because traditionally unmarried adolescents are not expected to initiate sexual activities until they are married. During the focus group discussion, it was highlighted by parents that going to such place will encourage promiscuity and that people will look down on them, calling them all sorts of names. This was in agreement with Akim J. Mturi (2001), where Lesotho culture discourages adolescents from visiting health centres because they are shy to be seen in need of reproductive health services prior to marriage. Those who have the courage to visit health centers sometimes receive a cold shoulder from providers.

In discussing the issues of parents communicating with their adolescents on sexual issues, many parents (69.6\%), neither supported nor disagreed with the discussion on sexual issues. These set of parents seems to be indifferent in their attitude but may have their reservation. However,(8.29\%) agreed that they discuss the issues with their wards while other (22.2\%), out rightly objected to discussing their issues.

This may be attributed to fear and erroneous belief that discussing sexual matters will promote uncontrolled sexual practices among the adolescents. In the focus group discussion the participants were asked if they had ever discussed sexual issues with their adolescent children, most parents in this group reported that they sometimes discuss the issues freely with their adolescents especially when there is a problem or reported case of death through abortion or unwanted pregnancy. Some parents in this focus group call our attention to fact that it is against the Bible for people to be involved in sexual activities or contraceptives before marriage. This finding agrees with Richard's (2001), Okanlawon and Ojinni (2009), report that few parents who have interest in discussing sexual matter with their children, still find it difficult and intimidating to talk about this sensitive issues.

The issue of introducing sex/family life education into the school curriculum was very controversial as most respondents $(54.4 \%)$, were not committed, and (15.5\% and $0.7 \%)$, put on an indifferent attitude, while (29.5\%), were quite committed. This shows that most parents will not encourage the teaching of sex openly is a taboo. Some parents in the fgd's felt sex education should be introduced into schools but government should take the lead in making the move, make it compulsory, and backing it up with legislation. Without this, the issue will not gain ground especially in the Christian based schools.

Finally, on who should provide sexuality information, most of the respondent (59.6\%), agreed that both parents and all stakeholders $(32.7 \%)$, should be the primary provider of sexuality information to their adolescents. This shows that parents have the opportunity of providing information and playing the natural roles assigned to them by nature as parents. This does not really mean that parents are actually playing their role correctly and accurately and at the right time as expected. If parents could play their primary role of providing sexuality education to their children, it will assist adolescents to prepare for parenthood. (Andre - Irivin 2000),

\section{Conclusion}

The findings of the study showed that most parents (40.4\%), have knowledge about adolescents sexual behaviour. Majority of the fgd's participants revealed that they are aware that unmarried adolescents' male or female have sexual partners. They further said it is not easy to know since they do not do it in open. Some of the FGDs participant said they do not know but guess that the adolescents have sexual relationships. A very minute participants says that says that their adolescent do not have sexual relationship because they are well cared for and are too young. The issue of communication has clearly revealed that most parents do not discuss sex related issues with their adolescents. Most are either shy or think that this will expose them to sexual activities. The same notion goes for the introduction of sex/family life education into school curriculum. Even though majority are against it because they think that teaching them will encourage promiscuity but support the idea that government should initiate the idea and back it up with legislation. Akim (2001), empirical studies have shown that communication of sex related matters or teaching sex/family life education in schools does not lead to promiscuisity. On the contrary, it has helped to reduce the rate of unwanted pregnancies, rate of abortion, delayed aging and rate of STIs including HIV.

\section{Recommendation}

Based on these findings the following recommendations are made: 
- That parent should be well groomed about sexuality matters through the mass media, conferences, parents/teachers association, jingles and the NGOs.

- The government should make it mandatory in all school curriculums and backed it up with legislation.

- The church should be given orientation.

\section{References}

Akim, J. M. (2001). Parents' Attitude to Adolescent Sexual Behaviour in Lesotho. Paper prepared for The XXIV General Population Conference -Brazil, 18-24. Unpublished Conference Paper.

Andrea, I. (2000). Taking Steps of Courage Teaching Adolescents about Sexuality and Gender in Nigeria and Cameroun, International Women Health Coalition, New York.

Cui, N., Minxiang, L., \& Ersheng, G. (2001). Views of Chinese parents on provision contraceptive services to unmarried youth. Reproductive Health Matters, 9, 137-145. http://dx.doi.org/10.1016/S0968-8080(01)90017-5

Lloyd, C.B. (2005). Growing up global: The Changing Transitions to Adulthood in Developing Countries. Washington DC, The National Academic Press.

Mench, B.S., Bruce, J., \& Greene, M.E. (1998). The Unchartd Passage: Girls'Adolescence in the Developing World. New York, Population Council.

Moronkola, O.A., \& Fakeye, J.A. (2008). Reproductive Health Knowledge, Sexual Partners, Contraceptive and Motive for Premarital Sex among Female Sub-Urban Nigerian Secondary Students in International Quarterly Community Health Education. Journal of Policy and Applied Research, 229-238.

Moronkola, O.A., \& Idris, O.M. (2000). Sexual Health Knowledge, Determinants of Sexual Behaviour and use of Contraceptive among Female Secondary School Students in Ibadan. Nigeria School Health, 12, 27 - 35.

Mturi, A.J. (2000). Adolescent Sexual Behaviour and Reproductive Health in Lesotho: A Case Study of Selected Areas. Study Report Submitted to the Union for African Population Studies (UAPS), Dakar, Senegal.

National Guideline Task Force (1996). Guideline for Comprehensive Sexuality Education in Nigeria, School Age to Young Adulthood. Action Health Incorporated, Lagos, Nigeria.

Okanlawon, I. O. (2009). Attitude of Parents in Ibadan North Local Government Area Oyo State Towards Sexuality Education for Adolescents. International Journal of Applied Psychology and Human Performance, 5, 916-931.

Richard, F.G. (2001). Knowledge and Attitude of Parents of Adolescent in Oritamefa Baptist Model Secondary School towards Family Life Education. Unpublished M.Ed. Project of the department of Human Kinetics and health education, University of Ibadan. 